\title{
Electrical microcurrent to prevent conditioning film and bacterial adhesion to urological stents
}

\section{Journal Article}

Author(s):

Gabi, Michael; Hefermehl, Lukas; Lukic, Danijela; Zahn, Raphael (D); Vörös, Janos; Eberli, Daniel

Publication date:

2011-04

Permanent link:

https://doi.org/10.3929/ethz-b-000028354

Rights / license:

In Copyright - Non-Commercial Use Permitted

Originally published in:

Urological research 39(2), https://doi.org/10.1007/s00240-010-0284-3 


\title{
Electrical microcurrent to prevent conditioning film and bacterial adhesion to urological stents
}

\author{
Michael Gabi • Lukas Hefermehl • Danijela Lukic • \\ Raphael Zahn · Janos Vörös · Daniel Eberli
}

Received: 1 April 2010/Accepted: 11 June 2010/Published online: 5 August 2010

(C) Springer-Verlag 2010

\begin{abstract}
Long-term catheters remain a significant clinical problem in urology due to the high rate of bacterial colonization, infection, and encrustation. Minutes after insertion of a catheter, depositions of host urinary components onto the catheter surface form a conditioning film actively supporting the bacterial adhesion process. We investigated the possibility of reducing or avoiding the buildup of these naturally forming conditioning films and of preventing bacterial adhesion by applying different current densities to platinum electrodes as a possible catheter coating material. In this model we employed a defined environment using artificial urine and Proteus mirabilis. The film formation and desorption was analyzed by highly mass sensitive quartz crystal microbalance and surface sensitive atomic force microscopy. Further, we performed bacterial staining to assess adherence, growth, and survival on the electrodes with different current densities. By applying alternating microcurrent densities on platinum electrodes, we could produce a self regenerative surface which actively removed the conditioning film and significantly reduced bacterial adherence, growth, and survival. The results of this study could easily be adapted to a catheter design for clinical use.
\end{abstract}

M. Gabi and L. Hefermehl contributed equally to this research.

M. Gabi · D. Lukic $\cdot$ R. Zahn · J. Vörös

Laboratory of Biosensors and Bioelectronics,

Swiss Federal Institute of Technology,

Gloriastrasse 35, 8092 Zürich, Switzerland

L. Hefermehl · D. Eberli $(\bowtie)$

Department of Urology, University Hospital Zürich,

Frauenklinikstrasse 10,8091 Zürich, Switzerland

e-mail: daniel.eberli@usz.ch
Keywords Catheter - Electrode - Current . Prevent bacterial adhesion · Film formation

\section{Introduction}

Urogenital catheters, including Foley catheters and urethral stents, are commonly used in patients with obstructive diseases to secure urine flow. For short-term use, the newer generation catheters offer good comfort with minimal complications. However, in situations where long-term catheters are needed, the rate of bacterial colonization, infection and encrustation remains a significant clinical problem. The foreign body serves as a bacterial reservoir, which can then trigger severe urinary infections requiring the administration of antibiotics and replacement of the catheter. Approximately, half of the patients with longterm indwelling catheters will suffer from complications of encrustation and blockage by bacterial films over time $[1,2]$. A prospective observation of 467 patients with Foley catheters in community care revealed 506 emergency referrals in 6 months [2], mainly due to catheter blockage. These procedures are a burden to the health care cost and significantly affect the quality of life of the patients.

Despite the knowledge on adherence and growth of bacteria, no stent material or surface coating completely resists the adherence of bacteria. Upon insertion of a prosthetic device in the urine tract, a conditioning film is formed on the surface of the device. The film, composed of proteins [3,4], electrolytes, and other organic molecules [5], is changing the device's surface properties and may provide receptor sites for bacterial adhesion [6]. Once the bacteria adhere to the biofilm, cell division and colonization starts and may lead to large coherent bacterial biofilms and encrustation [7]. This can then lead to super infection 
by opportunistic bacteria and to a rapid expanding infection often resistant to common antibiotics, especially if preceding antibiotic treatment has failed [8]. Biofilms offer an optimal environment for bacterial growth, since there is no immune response and the penetration of antibiotics is poor.

Many approaches to prevent biofilm formation and consecutive encrustation of urogenital catheters have been proposed with various outcomes [9-11]. Hydrophilic outer layers or coating with antibacterial agents such as rifampicin/minocycline or silver-ions have been used to make urethral catheters less attractive to bacterial colonization [12]. While drug eluting catheters were able to reduce bacterial growth, the formation of calcium phosphate encrustation could not be inhibited [10,11]. Further, the use of long-term antibiotic agents is associated with the development of resistant microorganisms.

Besides material research, other approaches tested were electric current to increase the efficacy of antibiotics against bacterial biofilms using high-frequency electric fields [13]. In 1969, Pareilleux and coworkers [14] first demonstrated the bactericidal effect of electric current. An electrified drain to sterilize the field of postoperative wound drainage was reported in 1993 [15, 16]. A newer catheter device that would resist encrustation by Proteus mirabilis biofilms required relatively high current that could only be provided at the tip of the catheter, where the fast corroding silver electrodes were located [17]. This catheter increased the amount of silver ions in the urine and was able to decrease the rate of encrustation significantly [17].

In this research, another electricity based strategy was applied to overcome the problem of bacterial adherence and biofilm formation. We have recently reported that eukaryotic cell migration and attachment can be prevented by applying small electric currents to conductive metal and metal oxide electrodes [18]. Either local electrochemical reactions increasing $\mathrm{H}^{+}, \mathrm{HClO}$ concentration, or altered layer deposition have inhibited the adhesion and migration of eukaryotic cells. By applying alternating small current density to platinum electrodes, we could produce a self regenerative surface which actively removed the conditioning film and significantly reduced bacterial adherence. The results of this study could easily be adapted to a catheter design for clinical use.

\section{Materials and methods}

Overall study design

To investigate the possibility of reducing the buildup of naturally forming conditioning films by applying different current densities, we designed a platinum electrode chip in
A
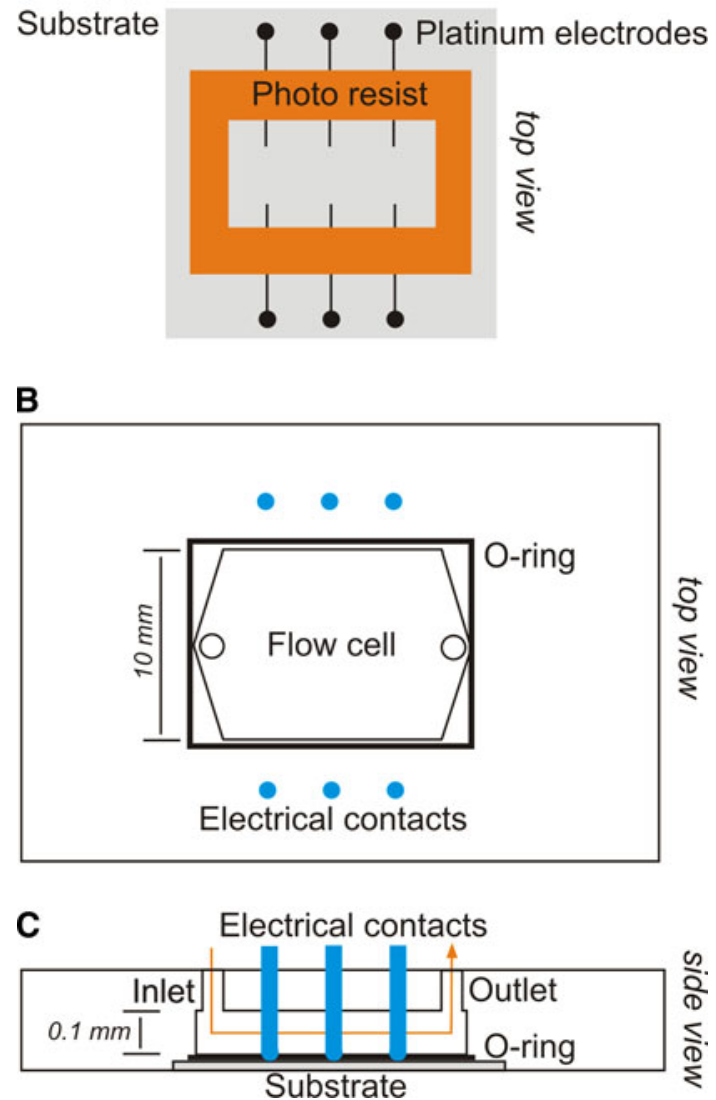

Fig. 1 Schematic representation of the custom built flow cell and platinum electrodes to test bacterial adhesion and film formation. a The glass substrate with six equal platinum electrodes on a microscopy cover slide insulated by a photo resist layer. b Top view of the flow cell with electrical spring contacts and silicone O-ring to prevent any leakage. c Side view of the flow cell with mounted substrate and urine flow direction indicated by the red arrow

a flow chamber. The film formation and desorption in artificial urine was analyzed by highly mass sensitive quartz crystal microbalance and surface sensitive atomic force microscopy (AFM). The dissolution behavior was later tested by dipping the formed films on the QCM crystal in acidic or basic solution. Finally, bacterial adherence, growth, and survival were assessed using a defined environment with Proteus mirabilis in artificial urine.

Platinum electrode chip and flow cell fabrication procedure

The chip was designed to contain six equal electrode surfaces inside the flow chamber (Fig. 1a). The substrate was fabricated using a glass microscopy cover slide that was cleaned for $5 \mathrm{~min}$ with Piranha solution, a mixture of $\mathrm{H}_{2} \mathrm{SO}_{4}$ and $\mathrm{H}_{2} \mathrm{O}_{2}$, to remove organic residues from substrates, then rinsed with $\mathrm{H}_{2} \mathrm{O}$ and blow dried with $\mathrm{N}_{2}$. The slide was heated on a hot plate at $200^{\circ} \mathrm{C}$ for $20 \mathrm{~min}$, 
immediately cooled down to room temperature and then spin coated with ma-N400 photoresist (micro resist, Germany) at 3,000 rpm for $30 \mathrm{~s}$. The slide was then pre-baked on a hot plate at $100^{\circ} \mathrm{C}$ for $2 \mathrm{~min}$ before exposing for $2 \mathrm{~min}$ in a Karl Süss X380 mask aligner through a polymer mask. The photoresist was developed in ma-D533/S solution (micro resist, Germany) for $30 \mathrm{~s}$ and rinsed in $\mathrm{H}_{2} \mathrm{O}$. The slide was etched in oxygen plasma for $3 \mathrm{~min}$ to remove any polymer residues after the rinsing and to increase the adhesion of the following metal layer. A thin film of titanium $(30 \mathrm{~nm})$ and platinum $(40 \mathrm{~nm})$ were deposited subsequently on the slide by physical vapor deposition (PVD) (Pfeiffer Classic 500, Wetzler, Germany). After deposition, the photoresist lift-off was performed in $N$-methyl-2-pyrrolidone (NMP) and the slide was cleaned with acetone, isopropanol and blow dried with $\mathrm{N}_{2}$. A layer of S1818 photoresist (Shipley, USA) was spin coated over the electrodes to insulate the electrode leads and present only $0.2 \times 1 \mathrm{~mm}$ platinum surface to the artificial urine.

The flow chamber was custom-built, made of PMMA and designed for hosting the chip substrate (Fig. 1b, c). Gold spring contacts enabled a simple access from outside the flow cell to the platinum electrodes. The flow chamber itself was sealed liquid-tight by an O-ring and has the dimensions $\quad$ width $=10 \mathrm{~mm} \quad(W), \quad$ length $=15 \mathrm{~mm}, \quad$ and height $=0.1 \mathrm{~mm}(H)$. A peristaltic pump (IPC, ISMATEC, Switzerland) was used to maintain a constant flow rate of $Q=200 \mu \mathrm{l} / \mathrm{min}$ (shear rate $=6 Q=W H^{2}=200 / \mathrm{s}$ ). The flow chamber was placed in an incubator at $37^{\circ} \mathrm{C}$ during the experiment, while the urine reservoir was placed outside of the incubator at room temperature. Selected currents were applied by the Autolab potentiostat (Eco Chemie, The Netherlands).

\section{Artificial urine and bacteria}

A concentrated $(5 \times)$ stock solution was prepared according to Griffith et al. [19] and accordingly diluted in $\mathrm{H}_{2} \mathrm{O}$ before starting the QCM-D experiment (see below). Before the flow cell experiment, an aliquot of Proteus mirabilis was diluted in $500 \mathrm{ml}$ sterile artificial urine. The aliquot was made by scratching the bacteria from the culture media and sus-

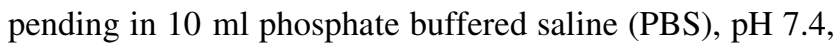
and stored in portions of $0.5 \mathrm{ml}$ at $-20^{\circ} \mathrm{C}$. The density of bacteria was determined by measuring the absorbance OD at $600 \mathrm{~nm}$ (McFarland Standard). The final concentration of bacteria used in the experiments was of $2 \times 10^{6} \mathrm{CFU} / \mathrm{ml}$.

Electrochemical quartz crystal microbalance with dissipation monitoring (EC-QCM-D)

The film formation was studied under an applied current using a QE 401 instrument with a QEM 401 electrochemical cell with platinum coated crystal QSX 314 both purchased from Q-Sense, Sweden. This instrument allows us to precisely quantify any mass adsorbed on the surface with a theoretical detection limit of $0.5 \mathrm{ng} / \mathrm{cm}^{2}$. The crystals were cleaned in $2 \%$ sodium dodecyl sulfate (SDS) for $30 \mathrm{~min}$, rinsed with $\mathrm{H}_{2} \mathrm{O}$ and blow dried with $\mathrm{N}_{2}$. The surface was cleaned in the final step in $\mathrm{UV} / \mathrm{O}_{3}$ treatment (UVO Cleaner, Jelight Inc., USA) for $30 \mathrm{~min}$. After mounting the crystal in the electrochemical cell (EC) of the QCM-D, artificial urine was pumped through the heated EC cell $\left(37^{\circ} \mathrm{C}\right)$ and the selected current was applied by an Autolab potentiostat (Eco Chemie, The Netherlands).

For flat, uniform and rigid films adsorbed on a QCM crystal, the measured change in resonance frequency is directly proportional to the adsorbed mass given by the Sauerbrey relationship [20]. In our case, some deviation from the Sauerbrey relationship was measured, due to the visco-elastic nature of the adsorbed film and its water content. By assuming a Voight model, using the 3rd, 5th, 7th, and 9th overtones according to Voinova et al. [21] and the software package Q-Tools (Q-Sense, Sweden), it was possible to calculate the "wet" mass uptake during the current applications.

\section{Atomic force microscopy}

The formed layers from the QCM experiment were investigated with AFM (NanoWizard BioAFM, JPK Instruments, Germany) and Mikromasch CSC38/noAl cantilevers (contact mode, set point $=0.2 \mathrm{~V}$ ). All the surfaces were analyzed in dry state. The surface roughness was measured on five different areas with the dimension $2 \times 2 \mu \mathrm{m}$, the $R_{\mathrm{RMS}}$ value was calculated and given with standard deviation in the corresponding AFM scan images. After the AFM measurement, the formed films were immersed subsequently in $1 \mathrm{M} \mathrm{HCl}$ and $1 \mathrm{M} \mathrm{NaOH}$ to test the dissolution behavior.

\section{Bacterial adherence and survival}

The flow chamber was custom-built, made of PMMA and designed for hosting the chip substrate. A peristaltic pump (IPC, ISMATEC, Switzerland) was used to maintain a constant flow rate of $200 \mu \mathrm{l} / \mathrm{min}$. The flow chamber was placed in an incubator at $37^{\circ} \mathrm{C}$ during the experiment, while the urine reservoir was placed outside the incubator at room temperature. Selected currents were applied by the Autolab potentiostat (Eco Chemie, The Netherlands). After the experimental time of 6 days, the cell viability and substrate were simultaneously stained with $16 \mu \mathrm{g} / \mathrm{ml}$ fluorescein diacetate (FDA) and $2 \mu \mathrm{g} / \mathrm{ml}$ propidium iodide (PI) solved in PBS [22]. The flow cell was rinsed with the staining solution for about $5 \mathrm{~min}$ before rinsing with PBS 


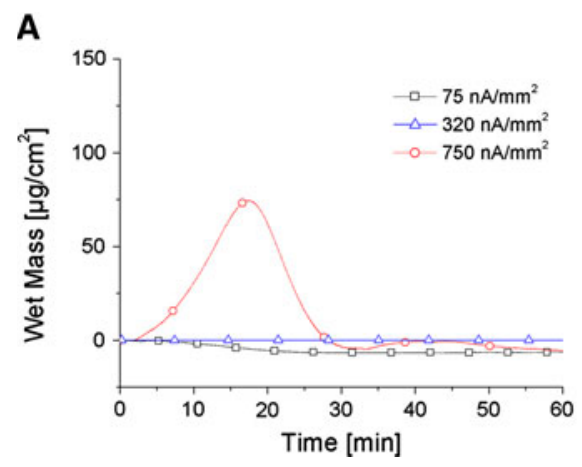

Fig. 2 Layer formation measured with QCM-D at different current densities applied to a platinum electrode in artificial urine. a An alternating current with a period of $4 \mathrm{~s}$ at $I=75 \mathrm{nA} / \mathrm{mm}^{2}$ led to desorption of material. No significant adsorption/desorption was observed at $I=320 \mathrm{nA} / \mathrm{mm}^{2}$ whereas $I=750 \mathrm{nA} / \mathrm{mm}^{2}$ showed a film formation of a transient film with a peak at $18 \mathrm{~min}$ before the film

and $10 \%$ formaldehyde in PBS for sample fixation. The substrate was blow dried with $\mathrm{N}_{2}$ and the electrode side was embedded in O.C.T ${ }^{\mathrm{TM}}$ Tissue Tek with a cover slide on top. The pictures were taken with a Zeiss LSM510 microscope equipped with an oil 63x/1.4 NA M27 planapochromat objective and EM-CCD camera from Hamamatsu.

\section{Results}

Electrochemical quartz crystal microbalance with dissipation monitoring (EC-QCM-D)

Different current densities were applied on the platinum coated QCM crystals and the amount of deposited material from artificial urine was monitored by the shift in the resonance frequency (Fig. 2a). Using the approximate values for the density $\left(1,000 \mathrm{~kg} / \mathrm{m}^{3}\right)$ and the viscosity $(0.001 \mathrm{~kg} / \mathrm{ms})$ of artificial urine, a fitting procedure based on the Voight model was applied and the wet mass increment of the adsorption process $\left(0.1368 \mu \mathrm{g} / \mathrm{Hz} / \mathrm{cm}^{2}\right)$ was determined. Using this value, the adsorbed wet mass of the formed layer was calculated from the observed changes in the resonance frequencies. The same fitting procedure was used to estimate the layer formation for both anodic and cathodic currents in Fig. 1. We applied an alternating current (period $4 \mathrm{~s}$ ) density of $I=75 \mathrm{nA} / \mathrm{mm}^{2}$ for $1 \mathrm{~h}$ and observed a slightly decreasing baseline (to $\Delta_{\max }$ wet mass $\left.=-6 \mu \mathrm{g} / \mathrm{cm}^{2}\right)$. Applying a current density of $I=320 \mathrm{nA} / \mathrm{mm}^{2}\left(\Delta_{\text {max }}\right.$ wet mass $\left.\leq 0.1 \mu \mathrm{g} / \mathrm{cm}^{2}\right)$, we $\mathrm{did}$ not see any significant adsorption. However, if a current density of $I=750 \mathrm{nA} / \mathrm{mm}^{2}$ was applied, the formation of a transient film with a peak $\Delta_{\max }$ wet mass $=74 \mu \mathrm{g} / \mathrm{cm}^{2}$ was observed after $18 \mathrm{~min}$. Then, the film desorbed with

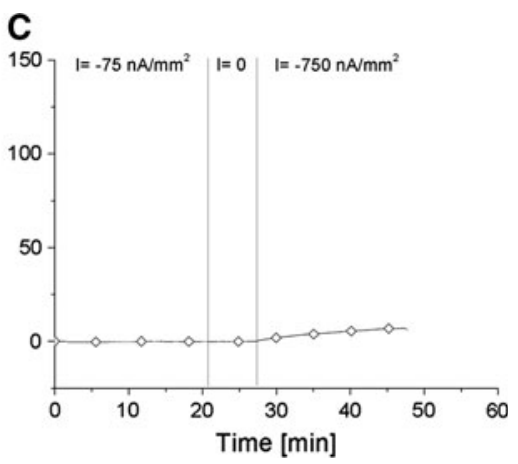

desorbed with almost the same rate as it has been formed. b A constant anodic current of $I=75 \mathrm{nA} / \mathrm{mm}^{2}$ showed a film formation reaching a plateau, while $I=750 \mathrm{nA} / \mathrm{mm}^{2}$ showed a steeper and continuous film formation. c A constant cathodic current resulted in a slight film formation only at the higher current density of $I=-750 \mathrm{nA} / \mathrm{mm}^{2}$

the same rate constantly as observed during formation. Applying a constant anodic current of $I=75 \mathrm{nA} / \mathrm{mm}^{2}$ showed a continuous film formation reaching a plateau at $\Delta_{\max }$ wet mass $=27 \mu \mathrm{g} / \mathrm{cm}^{2}$. Switching off the current $(I=0)$ did not change the layer thickness. Increasing the current density to $I=750 \mathrm{nA} / \mathrm{mm}^{2}$ resulted in a continuous film formation with no plateau within the course of the experiment. Applying a cathodic current density of $I=-75 \mathrm{nA} / \mathrm{mm}^{2}$ showed no film formation, whereas a ten times higher current density displayed a slight film formation in the range of $6 \mu \mathrm{g} / \mathrm{cm}^{2}$.

\section{Atomic force microscopy}

The platinum coated QCM crystals were gently rinsed with $\mathrm{H}_{2} \mathrm{O}$ and blow dried with $\mathrm{N}_{2}$ after the measurements. Macroscopically, the surfaces from the alternating and cathodic current experiment were clean, whereas the surface from the anodic current was covered with a bluish, oillike film. AFM revealed the lack of deposited residues on the surface with applied alternating current densities $I=320 \mathrm{nA} / \mathrm{mm}^{2}$ and $I=750 \mathrm{nA} / \mathrm{mm}^{2}$, respectively (Fig. 3b, c). The surface roughness after current became even lower than that of the new untreated platinum coated crystals (Fig. 3a). In contrast, the platinum surface after anodic current treatment clearly showed the presence of a film that started to delaminate from the surface (Fig. 3e) and wile scanning, a small fragment of the film was removed (Fig. 3e, square insert) indicating weak film adhesion. The surface exposed after the film removal had a surface roughness of $R_{\mathrm{RMS}}=1.9 \mathrm{~nm}$. Due to the small delaminated area, only one $2 \times 2 \mu \mathrm{m}$ region could be measured inside the hole. Therefore, no standard deviation is given. The roughness of the surrounding was also $R_{\mathrm{RMS}}=1.9 \mathrm{~nm} \pm 0.5$. The film thickness was around 

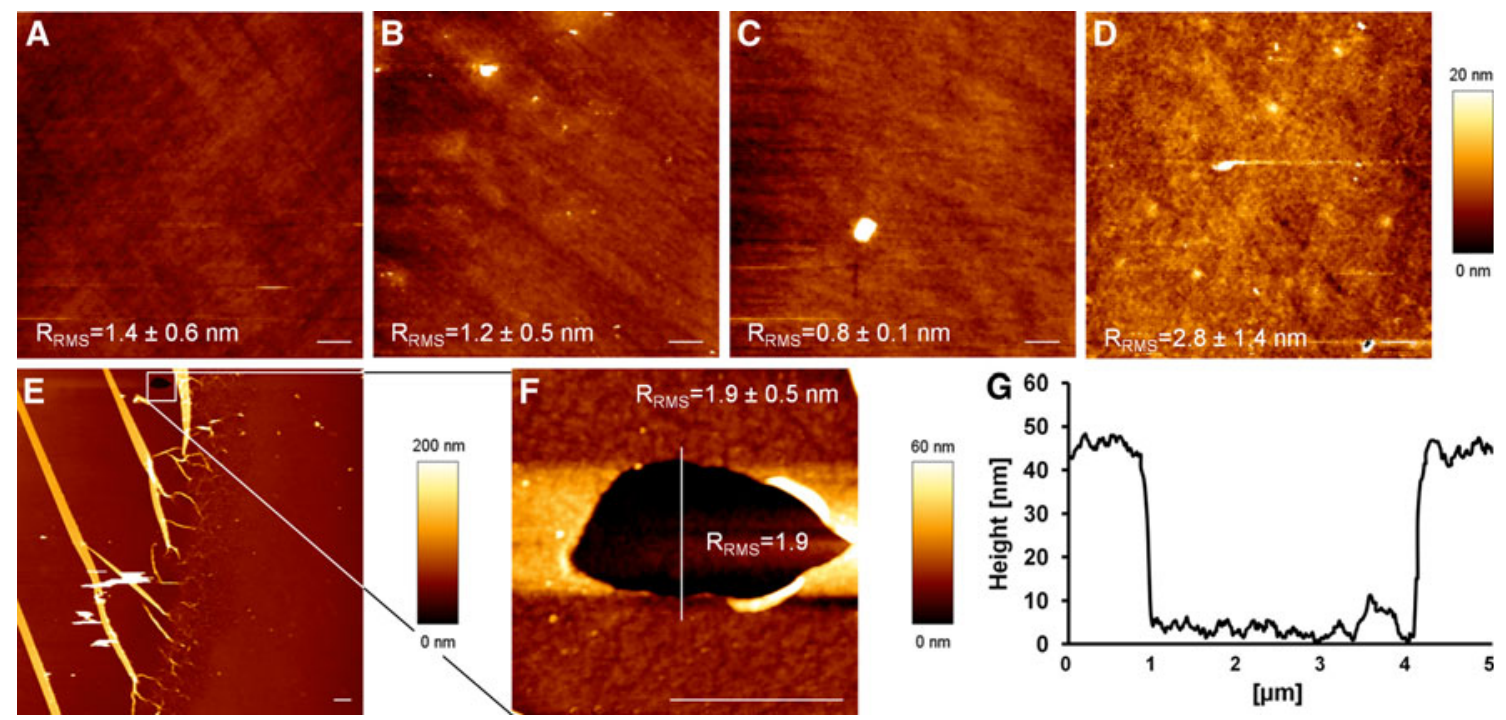

Fig. 3 Atomic force microscopy images of the platinum coated QCM crystal surface after applying different currents in artificial urine with the corresponding $R_{\mathrm{RMS}}$ value and dimension bar of $5 \mu \mathrm{m}$. a Surface of an untreated bare platinum crystal. b Surface after applying an alternating anodic current of $I=320 \mathrm{nA} / \mathrm{mm}^{2}$, c of $I=75$ and $750 \mathrm{nA} / \mathrm{mm}^{2}$, d cathodic current $I=75$ and $750 \mathrm{nA} / \mathrm{mm}^{2}$. e The

$50 \mathrm{~nm}$ in dry state (Fig. 3f and cross-section, Fig. 3g). After cathodic treatment, the surface showed an increase in surface roughness to $R_{\mathrm{RMS}}=2.8 \mathrm{~nm} \pm 1.4 \mathrm{~nm}$ (Fig. $3 \mathrm{~d}$ ).

\section{Dissolution behavior}

After the AFM measurement, the QCM crystals were immersed in an acidic and a basic solution to test their dissolution behavior. Surprisingly, a very thin film seemed to tear off from the surface of the QCM crystal treated with alternating current $I=750 \mathrm{nA} / \mathrm{mm}^{2}$ when immersed in acidic solution, while $I=320 \mathrm{nA} / \mathrm{mm}^{2}$ did not show any delamination of a layer. The anodic bluish, oil-like film remained in acidic solutions, while it was immediately dissolved in basic solutions. The cathodic QCM crystal showed no change in either of the solutions.

\section{Bacterial adherence and survival}

The experiment with Proteus mirabilis containing artificial urine was performed in a custom-built flow cell (Fig. 1) sealed onto a glass substrate with six equal platinum electrodes. Different currents (alternating current of $I=320 \mathrm{nA} / \mathrm{mm}^{2}$, anodic currents of $I=75 \mathrm{nA} / \mathrm{mm}^{2}$ and $I=750 \mathrm{nA} / \mathrm{mm}^{2}$ ) were applied under continuous urine flow. After 6 days, the substrate surface was stained for viable and dead cells (Fig. 4). Proteus mirabilis adhered to the control electrode with no current applied (Fig. 4a). Most of the cells were found alive (green, FDA positive) anodic current $I=75$ and $750 \mathrm{nA} / \mathrm{mm}^{2}$ induced film formation, which already started to delaminate, clearly visible in the image of the magnified square area. $\mathbf{f}$ The crack surface has the same $R_{\mathrm{RMS}}$ value as measured on the formed film. $\mathbf{g}$ The cross-section height profile of the crack inside the 50-nm thick film

and only a small fraction was dead (red, PI positive). On the electrode with alternating current of $I=320 \mathrm{nA} / \mathrm{mm}^{2}$, only few dead bacteria and some impurities were observed (Fig. 4b). On the electrode with a small anodic current of $I=75 \mathrm{nA} / \mathrm{mm}^{2}$ also only a few bacteria but a stronger green background signal was observed. At higher current density (i.e. $I=750 \mathrm{nA} / \mathrm{mm}^{2}$ ), a thick film started to delaminate from the electrode. The presence of spots in the image indicates that some bacteria might be incorporated in the film but it was not possible to evaluate their vital status due to the strong fluorescence of the film. The platinum electrodes were not compromised by the applied currents after 6 days and no corrosion artifacts were observed in transmission light microscopy (images not shown).

\section{Discussion}

Decades after the introduction of the first catheters to urology, long-term catheters remain to be a significant clinical problem. Biofilm formation, infection, and encrustation of catheters made from synthetic materials require the use of antibiotics and often stent replacements. Therefore, in this study, we have evaluated a novel approach applying microcurrents to electrodes to minimize biofilm formation and bacterial adherence.

First we developed a standardized in vitro model using a custom-designed chip with six platinum electrodes and flowing artificial urine. Among the different non-corrosive 
Fig. 4 Fluorescence microscopy images of four different study groups are shown after staining with FDA and PI to distinguish between viable (green) and dead (red) bacteria. Different current densities were applied to the platinum electrodes exposed for 6 days to artificial urine containing Proteus mirabilis. a No current $I=0$ applied, b alternating current $I=320 \mathrm{nA} / \mathrm{mm}^{2}, \mathbf{c}$ anodic current $I=75 \mathrm{nA} / \mathrm{mm}^{2}$

d anodic current

$I=750 \mathrm{nA} / \mathrm{mm}^{2}$
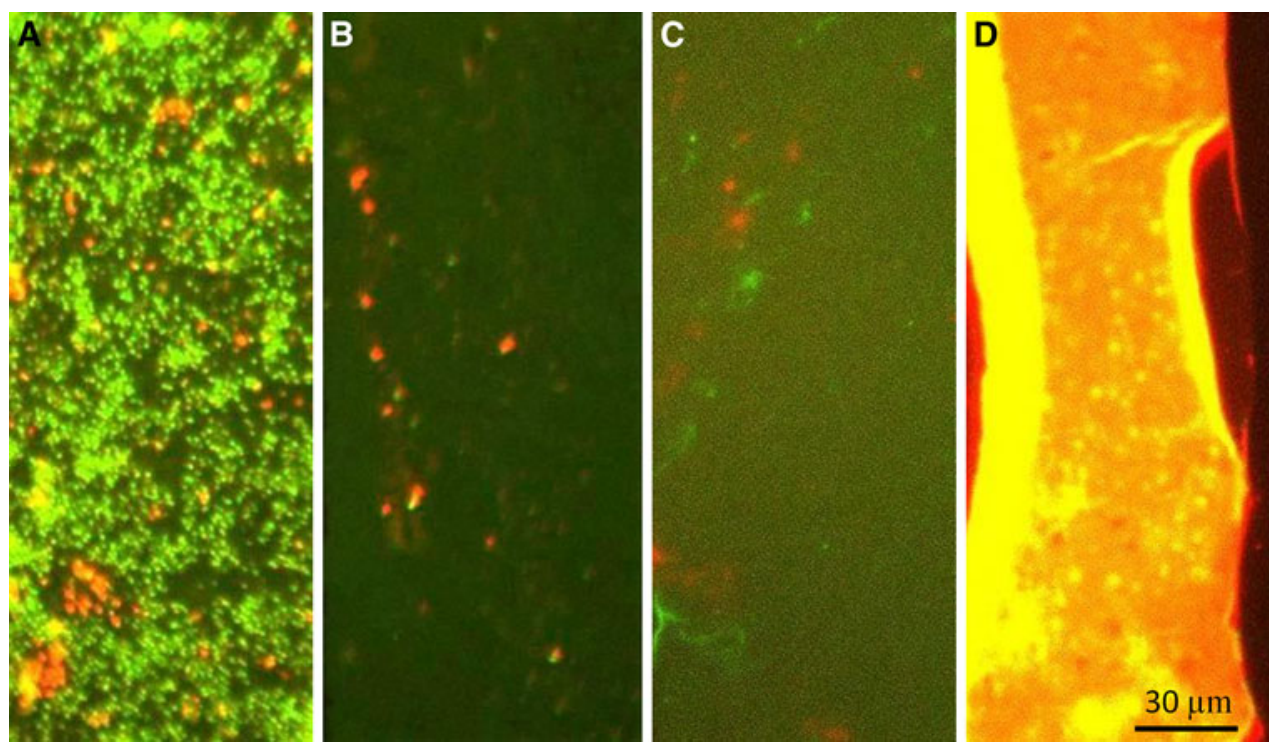

materials that could be used as electrode surface, stainless steel, gold, silver, and platinum are most common [23, 24]. For this feasibility study we decided to employ platinum electrodes because of their inert chemical characteristics [25]. In our model, the electrical power settings were set so low that no cytotoxic effect is expected on the mucosa of the ureter or urethra and the electrical energy applied is too low to be sensed by patients. The current density, rather than the potential, was kept constant to achieve a constant electrochemical product turnover. We used Proteus mirabilis because it is the most common bacteria to colonize catheter surfaces to form extensive biofilms leading to encrustation [26, 27]. Furthermore, Proteus mirabilis produces urease, which significantly increases the local $\mathrm{pH}$ levels by metabolizing urea to ammonia, thus inducing a precipitation of calcium- and magnesium phosphate. In principle, this strategy should be applicable to other bacteria causing urinary tract infections including Pseudomonas aeruginosa, Klebsiella pneumoniae, and Serratia $[26,27]$.

Applying alternating current to platinum surfaces showed different reactions on the adsorption of material, depending on the current densities; at low and moderate current densities we observed no significant mass changes on the platinum electrodes. Applying a high current density, we recorded an initial buildup of the film which was reduced thereafter without a change in current settings. This effect is probably due to weak interaction of the film with the surface, leading to partial delamination which is then averaged by the QCM and could not be observed in the AFM analysis due to the limited scanning area $(100 \times 100 \mu \mathrm{m})$.

Tests with anodic currents showed a continuous layer formation on the platinum electrodes. Similar findings were made on indium tin oxide electrodes showing increased adsorption of a polymer under an applied positive potential as reported by Bearinger et al. [28]. Even continuous adsorption of poly-(L-Lysine) under positive potential was reported previously [29]. These results were counterintuitive since the molecule and the surface were both positively charged and the reason for this observation is not yet clear. The authors suggested that the molecules interact less strongly with the surface when a potential is applied and therefore, are structured more loosely, resulting in a higher mass per area adsorption. In addition, the production of $\mathrm{HClO}$, due to Faradaic reactions, might crosslink lysine side chains of proteins leading to film formation on the electrode surface and explain the observed continuous adsorption [30].

The AFM analysis of the platinum QCM crystals showed a slight increase of the surface roughness on the formed film and within the delaminated area, indicating some partial residues on the bottom surface. But the highest surface roughness was measured after applying cathodic currents, which electrochemically induced high $\mathrm{pH}$ and might have caused precipitation of a layer of calcium- and magnesium phosphate as indicated by the mass uptake in the QCM data at the higher current density.

The dissolution behavior of the formed layer was tested by dipping in acidic or basic solution. Delamination of a barely visible film was seen when soaked in acidic solution only. The interaction force must be weaker in the presence of protons, indicating that the films must have been formed at basic conditions. This can be explained by the different standard reduction potentials necessary for the electrolysis of water at the anode $(1.23 \mathrm{~V}$ vs. NHE) and cathode ( $-0.83 \mathrm{~V}$ vs. NHE) [31] and the symmetric current pulse applied. More hydroxide was formed at lower potentials, 
than protons. As expected, the layer formed at anodic current was removed in basic solution.

These findings support the idea of using electric currents to prevent bacterial adhesion to urinary catheters and stents either by the electrochemical products due to Faradaic reactions and/or by altering the surface characteristics of the conditioning film. This technology could potentially be useful for all inserted urologic devices including Folley catheters, Double-J stents, Prostate Stents, and nephrostomy catheters. In order to apply microcurrent to the stents, the surface will have to be rendered conductive. This can be done by application of a conductive layer, e.g. silver or platinum. Further, for internal application, a micro-battery or an inductive device will be needed for energy delivery.

Our results on bacterial adherence and growth showed significantly decreased bacterial adhesion after 6 days in the case of application of alternating current $(I=320 \mathrm{nA} /$ $\mathrm{mm}^{2}$ ) and the expected layer formation at anodic currents, which started to delaminate at the highest current density. The film formation under applied electric currents is different compared to conditioning films formed under normal conditions. As indicated by our results, the likelihood of bacterial adhesion to such an altered surface might be lower than under normal conditions and the electrochemical products $\mathrm{H}^{+}, \mathrm{OH}^{-}$generated on the electrode surface create an unfavorable chemical gradient for bacterial colonization. Moreover, $\mathrm{HClO}$ is a strong oxidizer with bactericidal properties in the vicinity of the electrode, where antibiotics usually cannot be applied in high enough concentrations [6] and $\mathrm{H}^{+}$is changing the urine's $\mathrm{pH}$ to low values, preventing calcium- and magnesium phosphate precipitation. We did not observe any microscopic crystals on the electrodes throughout the experimental time.

In conclusion, we were able to show that the microcurrent applied to a conducting surface is effective in reducing bacterial growth in two ways. First, it can reduce the formation of the conditioning layer making bacterial adherence more difficult and secondly, by changing the microenvironment, preventing bacterial adherence and growth. This research can lead to a next generation of catheters with lower rates of biofilm formation, infection and encrustation.

Acknowledgments We also thank Mr. Martin Lanz, Mr. Steven Wheeler from ETH Zurich for their help making flow cell and platinum electrode substrates. We would also like to thank Damina Balmer M.Sc. for the editorial assistance.

\section{References}

1. Cools HJM, Van der Meer JW (1986) Restriction of long-term indwelling urethral catheterisation in the elderly. $\mathrm{Br} \mathrm{J}$ Urol 58(6):683-688
2. Kohler-Ockmore J, Feneley RCL (1996) Long-term catheterization of the bladder. Br J Urol 77(3):347-351

3. Canales BK et al (2009) Presence of five conditioning film proteins are highly associated with early stent encrustation. J Endourol 23(9):1437-1442

4. Santin M et al (1999) Effect of the urine conditioning film on ureteral stent encrustation and characterization of its protein composition. Biomaterials 20(13):1245-1251

5. Gristina AG (1987) Biomaterial-centered infection: microbial adhesion versus tissue integration. Science 237(4822): 1588

6. Tenke P et al (2004) Bacterial biofilm formation on urologic devices and heparin coating as preventive strategy. Int $\mathbf{J}$ Antimicrob Agents 23(Suppl 1):67-74

7. Denstedt JD, Wollin T, Reid G (1998) Biomaterials used in urology: current issues of biocompatibility, infection, and encrustation. J Endourol 12(6):493-500

8. Denstedt JD, Cadieux PA (2009) Eliminating biofilm from ureteral stents: the holy grail. Curr Opin Urol 19(2):205

9. Williams GJ, Stickler DJ (2007) Some observations on the diffusion of antimicrobial agents through the retention balloons of Foley catheters. J Urol 178(2):697-701

10. Schierholz JM et al (2002) Antiinfective and encrustationinhibiting materials - myth and facts. Int J Antimicrob Agents 19(6):511-516

11. Stickler DJ, Morgan SD (2008) Observations on the development of the crystalline bacterial biofilms that encrust and block Foley catheters. J Hosp Infect 69(4):350-360

12. Davis CP et al (1989) Effects of microamperage, medium, and bacterial concentration on iontophoretic killing of bacteria in fluid. Antimicrob Agents Chemother 33(4):442-447

13. Giladi M et al (2008) Microbial growth inhibition by alternating electric fields. Antimicrob Agents Chemother 52(10):35173522

14. Pareilleux A, Sicard N (1970) Lethal effects of electric current on Escherichia coli. Appl Environ Microbiol 19(3):421-424

15. Shafik A (1993) The electrified catheter. World J Urol 11(3):183185

16. Shafik A (1993) The electrified drain. A new device for sterilizing the field of drainage. Int Surg 78(4):357-359

17. Chakravarti A et al (2005) An electrified catheter to resist encrustation by Proteus mirabilis biofilm. J Urol 174(3):11291132

18. Gabi M (2009) Electrically controlling cell adhesion, growth and migration. Colloids Surf B Biointerfaces (submitted)

19. DP Griffith (1976) Urease, the primary cause of infection-induced urinary stones. Invest Urol 13(5):346-350

20. Sauerbrey G (1959) The use of quartz oscillators for weighing thin layers and for microweighing. Z Phys 155:206-222

21. Voinova MV et al (1999) Viscoelastic acoustic response of layered polymer films at fluid-solid interfaces: continuum mechanics approach. Physicia Scripta 59(5):391-396

22. Jones KH, Senft JA (1985) An improved method to determine cell viability by simultaneous staining with fluorescein diacetatepropidium iodide. J Histochem Cytochem 33(1):77-79

23. Davis CP et al (1992) Electrode and bacterial survival with iontophoresis in synthetic urine. J Urol 147(5):1310-1313

24. Spadaro JA et al (1974) Antibacterial effects of silver electrodes with weak direct current. Antimicrob Agents Chemother 6(5): 637-642

25. Mortensen BT, Bojsen J (1982) Evidence for growth inhibition by platinum electrodes at low current levels. J Biomed Eng 4(2):103-106

26. Stickler DJ (2008) Bacterial biofilms in patients with indwelling urinary catheters. Nat Clin Pract Urol 5(11):598-608

27. Chakravarti A (2005) An electrified catheter to resist encrustation by proteus mirabilis biofilm. J Urol 174:1129-1132 
28. Bearinger JP, Voros J, Hubbell JA, Textor M (2002) Electrochemical optical waveguide lightmode spectroscopy (ECOWLS): a pilot study using evanescent-field optical sensing under voltage control to monitor polycationic polymer adsorption onto indium tin oxide (ito)-coated waveguide chips. Biotechnol Bioeng 82(4):466-473

29. Ngankam AP, Van Tassel PR (2007) Continuous polyelectrolyte adsorption under an applied electric potential. Proc Natl Acad Sci USA 104(4):1140-1145
30. Gabi M et al (2009) Influence of applied currents on the viability of cells close to microelectrodes. Integr Biol 1(1):108-115

31. Lide DR (2007) CRC handbook of chemistry and physics a ready-reference book of chemical and physical data, 88th edn. CRC Press, Boca Raton,1 Bd 